\title{
A ESCOLA COMO ESPAÇO: IDENTIDADES DE GÊNEROS E SEXUALIDADES E SUAS HIERARQUIAS.
}

\author{
THE SCHOOL AS SPACE: IDENTITIES OF GENDER \\ AND SEXUALITIES AND THEIR HIERARCHIES. \\ L'ÉCOLE COMME ESPACE: IDENTITÉS DE GENRE \\ ET SEXUALITÉS ET LEURS HIÉRARCHIES.
}

\section{Benhur Pinós da Costa}

Doutor em Geografia pela Universidade Federal do Rio Grande do Sul. Professor adjunto da Universidade Federal de Santa Maria (UFSM), no Departamento de Geociências e no Programa de Pós-Graduação em Geografia e Geociências. Universidade Federal de Santa Maria, Departamento de Geociências. Av. Roraima, 1000, Cidade Universitária, Prédio 17, Departamento de Geociências Camobi.97105-900 - Santa Maria, RS - Brasil.e.mail: benpinos@gmail.com

\section{Resumo}

O texto discute a escola como espaço. Define espaço escolar pelo desenvolvimento de regras de apresentação dos corpos e construção de identidades hegemônicas e subalternas. Verifica a hierarquização das expressões de identidade no espaço escolar atentando os gêneros e as diversidades sexuais. Evidencia processos de reconhecimento das homossexualidades na escola e produção de um espaço de conflito entre identidades e suas hierarquizações. Discute a construção da identidade homossexual e o projeto de extensão e ensino produzido pelo grupo de pesquisa "Espacialidades Urbanas" da Universidade Federal de Santa Maria em uma escola da periferia da cidade de Santa Maria-RS. Apresenta uma proposta de atividades de ensino pautando as questões de gênero e sexualidades na escola. Apresenta uma proposta de atividades de ensino que enfoca as identidades de gênero e sexualidades na escola. Baseia-se na discussão de metodologias de ensino em Geografia das relações entre identidade e espaço, em especial, as identidades das homossexualidades. Apresenta o resultado da necessidade de discutir as relações da identidade homossexual relacionadas a outras esferas de identificação como, por exemplo, a religião.

Palavras-chave: escola, espaço, homossexualidades, gêneros, Geografia. 


\section{Abstract}

The text discusses the school as a space. Defines school space for development of rules bodies presentation rules and construction of hegemonic and subaltern identities. Checks the tiering of identity expressions at school paying attention genders and sexual diversity. Shows recognition processes of homosexualities in school and production of an space of conflict between identities and their hierarchies. Discusses the construction of homosexual identity and the extension and teaching project produced by the research group "Urban spatiality" of the Federal University of Santa Maria in a school of urban periphery the town of Santa Maria-RS. It presents a proposal for educational activities that focuses on gender identities and sexualities in school. It is based on the discussion of teaching methods in geography of the relationship between identity and space, in particular the identity of homosexualities. It presents the result of the need to discuss the relationship of homosexual identity related to other identifiable spheres, for example, religion.

Keywords: school, space, homosexualities, gender, Geography.

\section{Résumé}

Le texte traite de l'école comme un espace. Définit l'espace scolaire pour l'élaboration de règles pour la soumission des corps et la construction des identités hégémoniques et subalternes. Vérifie la hiérarchie des expressions d'identité à l'espace de l'école à ponctuer les genres et la diversité sexuelles. Affiche les processus de reconnaissance des homosexualités à l'école et la production d'un space de conflit entre les identités et leurs hiérarchies. Discute la construction de l'identité homosexuelle et le projet d'extension et de l'enseignement produit par le groupe de recherche «spatialité urbaine» de l'Université fédérale de Santa Maria dans une école en dehors de la ville de Santa Maria-RS. Il présente une proposition pour les activités éducatives guidées les questions de genre et de la sexualité à lécole. Il est basé sur la discussion des méthodes d'enseignement de la géographie de la relation entre l'identité et de l'espace, en particulier l'identité des homosexualités. Il présente le résultat de la nécessité de discuter de la relation de l'identité homosexuelle liée à d'autres sphères identifiables, par exemple, de la religion.

Mots-clés: école, espace, homosexualités, genre, Géographie. 


\section{INTRODUÇÃO}

Este artigo irá debater a experiência produzida em um projeto de ensino estabelecido em uma escola de educação básica ${ }^{1}$, no bairro Santa Marta, na cidade de Santa Maria-RS. O projeto fez parte do programa de bolsas de iniciação científica de PROLICEN, com ênfase à formação do licenciado, da Universidade Federal de Santa Maria-RS, no decorrer do ano de 2015. O objetivo principal do projeto foi trabalhar as questões de preconceito e discriminação em relação às homossexualidades e as divergências em relação às definições mais rígidas de expressões corporais referentes aos gêneros. $\mathrm{O}$ artigo objetiva, então, entender as relações entre construção do espaço escolar e a construção de hierarquia de identidades dos sujeitos pertencentes a escola na relação entre professores e professores, alunos e alunos e professores e alunos.

As ações de ensino foram constituídas tendo como base a ideia de que o espaço escolar representa um conjunto de relações sociais condicionadas pela presença, expressão e comportamento dos sujeitos constituintes. A ideia principal é que este espaço é conformado instavelmente por diferentes "presenças" que entram em disputa e que procuram se territorializar nos atos e nos corpos, em um constante jogo de poder observado em muito grande escala ou microterritório. Estas "presenças" representam um conjunto de discursos provenientes dos diferentes "atores" escolares, efetivamente estabelecidas na força de seus atos discursivos e nas normas e nas construções legais que regem a escola, nas quais são provenientes de outras esferas discursivas, ideológica e de poder (as normativas de instituições legais que regem a burocracia escolar). A escola é vista, então, como um espaço constituído por "estórias até agora" (MASSEY, 2009), cujos sujeitos trazem consigo diferentes estórias de vida trazidas de outros espaços e um conjunto de crenças e definições sobre "si" e sobre "os outros", que procuram se consolidar, mas que, pela diversidade de expressões existentes neste espaço, sempre estão fadadas ao fracasso e a transformação.

O texto irá discutir, em primeiro lugar, a questão da construção de hegemonias identitárias presentes nas relações escolares, principalmente em relação à marginalização de formas de identificação de gênero e orientações sexuais dissidentes e, em segundo lugar, a problemática construção da identidade homossexual no espaço escolar. Nestes dois grandes momentos de discussão, iremos tratar alguns aspectos vivenciados na atividade de ensino de Geografia e questões de gênero e sexualidades em uma escola da periferia da cidade de Santa Maria-RS. A composição de nosso artigo resulta em uma explicação da produção do espaço escolar como um paradoxo entre construções hegemônicas de identifi-

Não iremos explicitar o nome da escola, para preservar de divulgação o corpo docente e discente. 
cação e produção dos corpos dos sujeitos escolares e dissidências identiárias que lutam pelo reconhecimento. Apresentamos, assim, o escola como um espaço em disputa e em constaante transformação.

\section{O PROBLEMA: GÊNERO E SEXUALIDADES NA ESCOLA.}

Embora este espaço possa ser percebido como um emaranhado de discursos e de presenças expressivas que instabilizam constantemente definições e normas sobre diferentes aspectos da vida social, ele apresenta-se, momentaneamente, hierarquizado. Esta hierarquia poderá ser entendida como produto de um jogo de relações de poder que exercem influencia e convencimentos sobre como os corpos devem ser e se portar no espaço escolar. As hierarquias são organizadas pelas disputas entre sujeitos que se apropriam de diferentes "trunfos" (RAFFESTIN, 1993) para se constituírem como agentes privilegiados da construção de formas específicas de relações sociais e constituição de corpos neste espaço. É, neste sentido, que um espaço como um emaranhado de sujeitos em disputa vai se consolidando e, assim, se constituindo como um território que procura se estabilizar, mesmo que efemeramente - isto porque as disputas e as instabilidades sempre existirão. Podemos pensar que as relações hierárquicas são produzidas pelos sujeitos em disputas que lançam de trunfos de poder mais eficazes ou porque conseguem manipular instrumentos de poder já consolidados socialmente: os discursos e representações hegemonicamente construídas que versam sobre a normalização dos comportamentos e das expressões, assim como a existência de outras transgressivas no espaço social total.

É, neste caso, que existe um processo de construção de um espaço social que se totaliza definido por um padrão que, paralelamente, une sexo a uma organização binária de gênero. Foucault (1988) analisa que, em relação ao sexo, ocorreu, na história da constituição da sociedade moderna, uma intensa produção discursiva no campo da moral, da religião (judaico-cristão e católica) e, principalmente, da ciência. Isto irá descrever e relacionar, de forma minuciosa, corpos, desejos e expressões, criando, assim, formas eficazes de disciplina "do sexo". Criam-se representações possíveis e legais de estéticas e comportamentos e outras que se tornarão "desvios" destas possibilidades: as primeiras serão hegemonias discursivas que irão regir e legalizar as formas de relações sociais. É neste sentido que tanto sexo como gênero irá ser circunscrito na cultura moderna. Em relação à construção binária dos sexos e dos gêneros - produtos dos atos discursivos dos dispositivos das instituições modernas, segundo Foucault (1988) - entre "norma" e "desvio", o ato de poder designa o sexo como "pré-discursivo" ("um sexo natural”) e os gêneros como produtos culturais ligados a tais naturezas diferenciais (pautadas principalmente na constru- 
ção de uma estabilidade genital dual). Os sexos (genitais) duais definiriam formas corporais também duais e representariam complementaridades sexuais destinadas à procriação, de acordo com a força do discurso médico-biológico dotado de moralidade destinada ao regramento social da sexualidade e vinculada a propósitos ideológicos de constituição da família patriarcal burguesa. A cultura dos gêneros seria, então, condicionada a uma natureza do sexo e esta falácia seria inclusive reforçada pelas próprias teorias (inclusive as feministas) que iriam problematizar as relações de poder entre gêneros (o poder do masculino), de acordo com Butler (2010).

Se os gêneros serão organizados de uma forma binária e se o polo de poder se concentra no masculino (fruto de um poder discursivo pautado no poder dos homens, como condição fundamental da economia política moderna, pautada na hereditariedade patriarcal) todas as divergências desta hegemonia seriam minuciosamente hierarquizadas, denotando algo que se difere a um modelo padrão de civilidade, e catalogadas como diferenças rigidamente definidas ou como desvios a estrutura binária das diferenças. Para Arigaray (apud BUTLER, 2010, p. 29) "tanto o sujeito como o outro são esteios de uma economia significante falocêntrica e fechada, que atinge seu objetivo de totalizante por via da complexa exclusão do feminino". O masculino se define e define o outro feminino, assim, segundo a autora, o feminino não se constituía como gênero, mas como uma diferença produto da hegemonia do gênero em uma economia simbólica falocêntrica. Assim, se instaurou uma ordem compulsória do sexo-gênero-sexualidade que produz identidades sexuais e de gênero a partir de crenças naturalizadoras das formas binárias, que polarizam expressões de corpo e desejos sexuais.

Além dos contrastes que definiram os gêneros masculino e feminino, pela naturalização das formas corporais e das genitálias que são tidos como atributos naturais inquestionáveis, não imersos em determinadas formas de entender as próprias conformações e produções do corpo e suas partes - determinadas pelas ciências médicas e biológicas, no caso do corpo e seus componentes, e pelas ciências humanas, no caso dos comportamentos que se encaixam a naturalizações dos corpos -, se construiu uma "herossexualização compulsória" (BUTLER, 2010). A construção de um modelo heterossexual como norma se atrela paralelamente a definição de que os sexos naturalizados estão ligados a formas de corpo e expressões masculinas e femininas que, por sua vez, estão relacionados aos papéis de gênero e as causas e consequências da procriação. A representação dos sexos como "pré-discursivos" permite justificar a ordem discursiva das maneiras possíveis de construção dos corpos e dos seus papéis sociais, reforçando-as com vistas à organização da procriação como base de interesses da organização da família burguesa patriarcal e todo seu aparato ins- 
titucional de constituição do Estado, nos primórdios de organização da propriedade privada e do modo de produção capitalista, que tem nela sua instituição fundamental (ENGELS, 1982). Além de uma ordem feminista que critica o gênero como construção cultural na célebre frase de Beauvoir (1980), "não se nasce mulher, torna-se", tem-se o sexo como também constituição de um conjunto de discursos que produzem sua naturalização (FOUCAULT, 1988; BUTLER, 2010). A partir do momento que pensamos criticamente a produção discursiva destas normas organizadas de forma binária, tornamos instáveis suas realizações e liberamos diferentes formas de identificações de gênero e produção de sexualidades de diferentes contextos sociais que estão sendo classificados como minorias.

A ordem discursiva que distingue diferentes sexos e define diferentes atributos e papéis de gênero são representações construídas historicamente e configuram-se nas possibilidades de linguagem, ou seja, de nomear e classificar, perante as relações diretas e face a face, os sujeitos e seus corpos (SILVA, 2000). Os referenciais linguísticos apresentam relação estreita com as formas institucionalizadas de produção dos significados do mundo e são provenientes das relações de poder que reproduzem tais significados. A linguagem produz formas inteligíveis do mundo e conduzem a identificação das coisas e dos sujeitos deste mundo perante os seus próprios padrões, em um sistema de igualdades e diferenças restritas, conduzidas pela organização binárias das normas e dos entendimentos.

Para Derrida (apud SILVA, 2000) o signo é um sinal ou uma marca que está no lugar da coisa, mas não coincide com tal coisa, sendo uma ausência ou uma não-presença da coisa em si. Desta forma, o signo da linguagem substitui a coisa em si a tal modo que não vemos mais a presença, mas somente o signo, constituindo uma metafísica da presença. A coisa ou as coisas que definem as predisposições dos outros ou dos sujeitos sociais nunca é plenamente realizada e ela é constantemente adiada pela forma simbólica que a define. Para se produzir, o signo precisa carregar tanto os traços que o definem como os traços que não o constituem e, assim, criam outras coisas simbólicas pelo efeito de diferenciação e de contraste, quase sempre constituído de polarizações sobre normas de possibilidades de ser e contrastes de desvios. Assim se constituíram as definições de outros não possíveis à norma rígida que liga os gêneros masculino e feminino, a partir do paralelismo com o sexo biológico e a construção da sexualidade pela procriação: pelo amor romântico; pelas expressões de masculino forte e bravo e feminino dócil e meigo; e pelos papeis de homem mentor superior da família e da propriedade e mulher esposa romântica e mãe carinhosa condicionada aos afazeres da casa (GIDDENS, 1993). Além destas generificações dos corpos, outros transgressores também constituíram-se de um corpo simbólico facilmente identificável além da simples presença, ou seja, um conjunto de minorias determinadas e nomeadas pela heterossexualidade compulsória. 
As homossexualidades escapam da norma vigente e promovem uma descontinuidade da sequencia sexo/gênero/sexualidade e, assim, são colocadas como exemplos de um conjunto de minoria aparentemente determinadas e representadas por um conjunto de traços simbólicos criados pelos próprios atributos do mesmo hegemônico, ou seja, a heterossexualidade compulsória. A partir de uma forma dialética, Butler (2010) nos explica que os "outros minoritários" de uma ordem compulsória masculina e heterossexual são criados nos contextos destas próprias ordens e seus conjuntos de manipulações simbólicas realizadas no campo do estabelecimento dos significados linguísticos que classifica a todos. A realidade das relações sociais é, assim, configurada pela não presença das coisas, mas a realização simbólica dos significados em si. Assim se produzem os mesmos hegemônicos, capazes de tomarem para si os constructos simbólicos hegemônicos, e os outros hegemonizados, cujos parâmetros de desvio e de não normalidade são dispersos pelos próprios discursos movimentados perante os outros próximos e tomados, com muito sofrimento, em si. A identificação dos pressupostos simbólicos da heterossexualidade e da masculinidade só é permitida, simbolicamente, por um conjunto de imaginários manipulados discursivamente pela estética da linguagem que definem outro não possível, desviante ou, então, em algum grau hierárquico inferior, como o homossexual e a mulher. É assim que se conduzem as relações cotidianas dos corpos, segundo Heller (1991), conduzidos por objetivações, ou seja, existem “objetivações genéricas em si”, ou os corpos inseridos nas formas e nas funções sociais, conduzidos a pensarem e a agirem de acordo com ordens organizadas complexamente na estrutura multidimensional do espaço social, e as “objetivações genéricas para si”, ou as instituições que produzem a configuração do social e dos corpos contidos nas diversas formas objetivadas dele (a ciência, o Estado, o capital, as classes de poder, a produção dos discursos e das ideologias). O cotidiano como esfera de alienação é a relação intrínseca entre as duas formas de objetivações e ele serve para disciplinar, alienar e particularizar os corpos.

As homossexualidades, para Louro (1997), como fazendo parte de uma minoria representada simbolicamente pela linguagem normativa, estão sempre à margem das representações e ações estabelecidas nas instituições e contextos sociais diferenciados, principalmente nas preocupações curriculares das escolas na atualidade. Os mesmos discursos e conjuntos simbólicos que definem a homossexualidade pelo viés autoritário dos sistemas significativos da heterossexualidade compulsória, produzem também as formas com que se relacionam professores (as) e professores (as), alunos (as) e professores (as) e alunos (as) e alunos (as). Além disto, os mesmos conjuntos simbólicos inquestionáveis não se ocupam em uma crítica radical da construção das identidades dos sujeitos escolares e dos documentos e materiais pedagógicos utilizados nestes contextos. 
A escola, assim, torna-se um território por excelência de reprodução de uma linguagem que polariza e hierarquiza os gêneros e as sexualidades, constituindo normas discursivas reproduzidas de modelos que preservam as formas hegemônicas de representação do masculino e da heterossexualidade compulsória. A reprodução hegemônica de discursos imaginários sobre os atributos, as estéticas e as formas de comportamento sobre os gêneros e sobre as sexualidades separam-se radicalmente da diversidade de possibilidades de representações e manipulações simbólicas diversas trazidas pelos sujeitos todos que se encontram na escola. Ocorre um abafamento institucional que cria um espaço discursivo e simbólico que escapa e reprime as coisas mesmas, ou seja, a realidade diversa dos sujeitos escolares.

Assim se configura a forma territorial do espaço escolar. Primeiro, como um campo de diversidades significativas da própria manipulação simbólica dos aspectos diversos da vida produzida por cada sujeito social que vem se relacionar neste espaço. Segundo, por um esforço de reprodução discursiva e simbólica dos agentes escolares hegemônicos - professores (as) e outros (as) alunos (as) cujos corpos e desejos se atrelam de forma pouco contraditória ao campo simbólico da heterossexualidade compulsória, ou outros (as) alunos (as) e professores (as) que, mesmo entrando em contradição à forma compulsória, a incorporam por desconhecimento e/ou necessidade de manter a aparência - que se asseguram dos discursos e formas simbólicas dominadoras da heterossexualidade compulsória para regrarem os comportamentos e expressões de corpos nas relações diárias dos afazeres diversos e obrigações escolares. Terceiro, pelo conflito cotidiano que desestabiliza a realização do imaginário definido pela linguagem e representações hegemônicas, trazendo disputas no campo das relações diretas em sala de aula, na configuração das normas escolares e nas importantes desavenças, muitas vezes não levadas em conta, nos espaços e tempos de relações banais contidas nos intervalos das aulas nas salas dos (as) professores (as) e no pátio de recreação dos alunos.

Este território que representa a escola é um complexo de formas de significação dentro de uma hegemonia de linguagem que privilegia alguns e marginaliza outros tantos, tidos como minorias que devem se adequar aos parâmetros de bom comportamento escolar. O corpo feminino deve ser vigiado em disparidade em relação ao corpo masculino, as expressões de desejo homossexuais devem ser contidas e as formas estéticas dissidentes que não constituem polarizações generificadas serão repudiadas. O grande problema é a incapacidade de se trabalhar a diversidade e deixar que a diversidade se propague como uma oportunidade criativa de critica radical a instituição dos poderes que alienam e produzem sofrimentos a todos: um campo imaginário que serve para reprimir e institui pola- 
rizações entre certo e errado e que são devastadoras das autenticidades sociais. No entanto, a escola é um caos e um campo de disputa que nunca cessará, pois o esforço de reprodução simbólica de uma heterossexualidade e masculinidade compulsória sempre estarão fadados ao fracasso, porque as margens contestarão constantemente os discursos homofóbicos e machistas de muitos dos sujeitos sociais que pensam que estão eles mesmos falando de si e representando a si. Os próprios discursos repressivos não representam exatamente o emissor do discurso, porque o conjunto de suas experiências reais é diverso, mas sim a aparência de pertencer a uma polarização do campo simbólico hegemônico e servir de forma confortável, sem questionamento sobre si mesmo, a este campo.

É por este sintoma de hierarquização e marginalização das expressões diversas de sexualidade dentro da escola que o campo da Geografia, com suas bases feministas, deverão agir e é nestes parâmetros que organizamos o projeto de ensino "Geografia, pluralidades culturais, gênero e orientação sexual: práticas de ensino para reconhecimento social das alteridades culturais e individuais". Este projeto foi desenvolvido no território de disputa de uma escola de periferia urbana, no bairro Santa Marta, na cidade de Santa Maria-RS, no ano de 2015. O projeto se organizou em quatro eixos de ação: o eixo teórico, em que discutimos conceitos e teorias sobre gênero e sexualidade; o eixo artístico, cujo objetivo foi trazer filmes e documentário que provocassem uma instabilidade as construções discursivas hegemônicas sobre as representações de gênero e sexualidade; o eixo "vida real", cujo propósito foi trazer sujeitos lésbicas, gays, travestis e transexuais para a escola para falarem de suas vidas e seus cotidianos na cidade de Santa Maria; e o eixo integração, cujos resultados e aprendizados iriam ser revisitados na forma de expressões individuais sobre os assuntos debatidos. Este projeto conseguiu se estabelecer de forma mais tranquila no primeiro semestre de 2015, não conseguindo continuar no segundo semestre em virtude de eventos de greve dos professores. Mesmo durando um semestre conseguimos ter encontros periódicos com turmas de alunos de ensino médio e com professores em períodos de reunião docente. O projeto nos revelou uma série de problemáticas e surpresas que nos fez refletir neste artigo a escola como espaço de reprodução e conflito em relação a um campo simbólico de representações de gênero e de orientações sexuais.

\section{0 “RECONHECIMENTO SOCIAL” DAS DIVERSIDADES SEXUAIS NA ESCOLA E A PROBLEMÁTICA DA CONSTRUÇÃO DA IDENTIDADE SEXUAL HOMOSSEXUAL}

Um dos pressupostos teóricos da etnometodologia (TEDESCO, 2003) se refere à capacidade dos atores sociais interpretarem os contextos em que vivem e se construírem, nos conjuntos de significados objetivados pelas relações sociais, nestes contextos. Para esta ciência, as localizações dos sujeitos em contextos sociais diferenciados determinam os

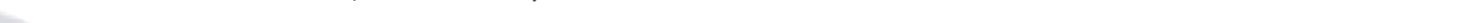


sentidos e as práticas das apresentações individuais. Estes contextos representam um conjunto de situações de ação nos quais todos estão submetidos e cujo agir rotineiro é interpretado à luz dos significados das práticas, dos objetos e dos corpos em interação. Estes significados são reproduzidos de forma localizada pela linguagem em prática, que institui um conjunto de leis correntes que permitem o fluir das relações sociais. Novamente, o que opera é um conjunto de trocas cujos sentidos das ações e dos corpos em movimento estão submetidos a produção complexa de um espaço simbólico que significa todos em interação, antes efetivamente da realidade. Por outro lado, a realidade da interação opera estes significados, tornando-os também flexíveis.

Este espaço simbólico é uma produção anterior à realidade (a realidade está sempre sendo adiada, conforme vimos em Silva, 2000). Para Garfinkel (2006) os sujeitos tem pouca consciência de suas ações e das suas definições quanto aos outros, porque não refletem e não teorizam sobre seus comportamentos, formas de agir e significar, isto porque estão reproduzindo um conjunto simbólico estruturado no próprio seio das relações localizadas. No entanto, ao mesmo tempo em que existem os imponderáveis das normas simbólicas situadas que regem as relações sociais e que definem práticas e corpos antes de suas realidades, isto representa sempre um universo em dissolução, porque os subentendidos rotineiros são valorados diferenciadamente, o que permite uma série de transgressões sobre as regras tácitas de um contexto interacional. Isto evidencia que os contextos sociais são territórios de produção local de inteligibilidades acionados nas relações sociais práticas e determinados pelos jogos de significação emanados pelos enunciados de linguagem dos sujeitos sociais em suas diferentes posições de poder e de convencimento.

Estes jogos são jogos de linguagens significativas que estão sempre em posição de incertezas, porque, para se constituírem, precisam ser repetidos pelos enunciados, pelos corpos e pelos atos dos agentes sociais, ou seja, performatizados (BUTLER, 2010). O poder de tornar repetido o significado das coisas reais é evidenciado nas capacidades enunciativas dos sujeitos sociais em seus jogos de interação. Estas capacidades representam a mobilização de "trunfos" de poder (RAFFESTIN, 1993) dos sujeitos que se hierarquizam e conseguem constituir tais "subentendidos rotineiros" (HERPIN apud TEDESCO, 2003) a partir da institucionalização deste poder. Isto se aplica ao caso do corpo burocrático e discente de uma escola: ocorre a mobilização de "significados de fora" do contexto interacional - como significados trazidos de representações hegemônicas da totalidade social - que asseguram a imaginação da composição de uma maioria e/ou são reforçados pelos dispositivos comunicacionais das banalidades dos sistemas de informação e construção ideológicas sociais. 
As relações entre alunos, além da relação entre corpo docente e discente, representam esta mobilização de significados que se produzem de forma hierárquica, ou seja, mobilizam sujeitos que reproduzem significados normativos e sujeitos que são evidenciados como "de fora" destas normas. O esforço destes jogos é criar normas simbólicas de significação de corpos, a partir da repetição performática da fala e do comportamento, e significações dissidentes que deverão ser, pelo próprio ato de simbolizar a realidade dentro do próprio contexto interacional, repudiadas e discriminadas. Além de uma uniformização contextual de um território simbólico, as dissidências deverão ser perfomatizadas para se constituírem como modelos que servirão para reforçar os enunciados simbólicos da hierarquia de poder instituída. Assim, as relações sociais em contextos escolares reproduzem a norma heterossexista e machista perante estes jogos de representações que, ao mesmo tempo em que discrimina e combate as outras representações de gênero e de orientação sexual, tomam estas como evidencias simbólicas corporificadas necessárias para reforças às hierarquias de poder. $\mathrm{O}$ resultado disto é o sofrimento àqueles hierarquizados de forma subalterna, que serão identificados pelos simbolismos do incorreto e do desviante, estando em um "limbo" que ao mesmo tempo força a significação da norma necessária ao seu corpo, mas também o coloca na contradição marginal desta.

Mas aqui nós temos um problema, será que as identidades hierarquizadas produzidas em contextos significativos regidos por enunciados de normalização representam a totalização e equilíbrio de um território de existências individuais como a de uma escola? Será que o outro marginal produzido pelo discurso de representação da norma viverá e se constituirá sempre pelo sofrimento que reforça a normalização? Para Mead (apud HONNET, 2003), o surgimento do sujeito psíquico está relacionado às dificuldades de interpretação das situações constituídas como problemas do mundo prático, possibilitando, assim, a origem de um mundo da subjetividade transgressiva independente da objetividade das situações práticas. Ocorre, neste sintoma, a separação entre privado e público, nos quais os conjuntos simbólicos emitidos pelas relações de linguagem, que produzem os sujeitos como desvios à regra, são subjetivados em um mundo privado de indagações sobre si mesmo e sobre os outros e as situações que o rodea, no qual ele mesmo é posição desviante de reforço à norma. O par dialético que assola o sujeito na interdição de seu corpo e de suas perspectivas que, ao mesmo tempo, serve para determinação da polarização necessária da norma, vai determinar um acúmulo de reconsiderações para tais situações e produzir uma iniciativa de reação prática. Assim, Mead (apud HONNETH, 2003) entende a reação como um esforço psíquico de conhecimento sobre os sentidos que são definidos aos seus comportamentos pelos outros nas situações comuns de ação. Isto gera um processo de autoconsciência e de necessidade de dispor de um saber sobre os significados in- 
tersubjetivos de suas ações e como elas se constituem como estímulo ao outro que as confronta. Aí se estabelece um processo fundamental de pergunta descrito por Mead (apud HONNETH, 2003, p. 129): "do que meu gesto significa para o outro, eu posso me conscientizar ao produzir em mim mesmo, simultaneamente, seu comportamento de resposta".

Para Honneth (2003), este processo apresenta dois vieses teóricos: o primeiro, no esforço teórico em Hegel, o espelhamento das normas sociais instaurados pela comunidade linguística representará as significações corporizadas dos sujeitos divergentes que servirão para a educação destas divergências e reconstrução dos significados normalizados nos seres reativos; por outro lado, na discussão em Mead, o indivíduo reage à comunidade linguística de significados práticos hegemônicos. Para isto, Honneth (2003) utiliza-se da didática de Mead que separa o "me" e o "eu”. O "me" são todas as reações práticas de reconhecimento das representações simbólicas hegemônicas e convergência à comunidade, como necessidade de inserção e reconhecimento como sujeito pertencente. O "eu" são as reações individuais as construções desta comunidade e que contrapõem o "me" como algo que não é somente sensibilidade moral (necessidade de ser reconhecido como membro em um conjunto de significações hegemônicas), mas algo de "natureza pulsional pré-social, de imaginação criadora" (HONNETH, 2003, p. 140). O “eu” produz a sensibilidade de si e das incompatibilidades das normas intersubjetivamente reconhecidas em seus contextos sociais. Mas então, como estas incompatibilidades poderão ser operadas na transformação dos contextos sociais e sobrevivência dos sujeitos criativo e incompatível, uma vez que suas incompatibilidades podem servir, exatamente, para reforçar a normalização significativa hegemônica da comunidade existente? A primeira ideia é que este processo de reforço pela evidência do desvio não é um processo tranquilo assim. Os significados hegemônicos não se estabilizam sempre e as diferenças hierarquizadas não se mantêm sempre em hierarquia, embora o esforço de manipulação do território simbólico se utilize sim dos contrários para sobreviver. Vão existir outros processos de significação e identificação dentro destes contrastes combinados que tornaram as relações sempre incertas e os contextos normalizados sempre em dissolução. Mas como se dá isto da esfera do sujeito marginal significado hegemonicamente à possibilidade da ruptura e sua emergência empoderada?

Este aspecto se apresentou como o ponto de partida da organização do projeto de ensino na escola da perifeiria urbana de Santa Maria-RS. Neste artigo, eles representam como elemento de reflexão sobre os projetos de ensino de Geografia sobre as diversidades sexuais. Nosso objeto é subsidiar as reflexões dos professores e agentes escolares no tratamento das questões das homossexualidades na escola. Dessa forma, apontamos as se- 
guintes questões: 1) quais as experiências de vida dos sujeitos orientados sexualmente para o mesmo sexo que se constituem como um conjunto de sofrimentos da ordem simbólica partidas de discursos estabelecidas nas relações práticas que reforçam o poder masculino e heterossexista?; e 2) quais as situações práticas de rompimento da ordem simbólica hegemônica binária e performática e retomada de novos sentidos sobre as condições singulares de vida e empoderamento na construção de novos significados transgressores a ordem heterossexista e misógina vigente? Para responder isto teríamos que passar as situações e evidência de novos discursos sobre as relações práticas de empoderamento de sujeitos homossexuais. Estes discursos deveriam se apresentar como a emergência de novos significados à ordem heterossexual compulsória vigente perante o território discursivo escolar e tornar instável a normalidade de suas condições. Mas como adentrar a estas novas construções simbólicas e instabilizar o espaço simbólico hegemônico existente? A ideia principal foi partir para a divulgação de novas estórias de vida na construção conturbada das homossexualidades, mediante apresentação de situações reais passadas de sujeitos homossexuais. Quem seriam estes sujeitos?

Bom, o grupo de pesquisa "Espacialidades Urbanas", do departamento de Geociências da Universidade Federal de Santa Maria, em seus aproximadamente seis anos de atividades de pesquisa, ensino e extensão, envolvendo-se com as discussões sobre gênero, sexualidades e pluralidades culturais, conseguiu estruturar um conjunto de discursos pela coleta de narrativas de sujeitos homossexuais de diferentes cidades do estado do Rio Grande do Sul e de outras localidades brasileiras. Além das pesquisas, as atividades de extensão junto ao movimento LGBT (Lésbicas, Gays, Bissexuais, Travestis e Transgêneros) de Santa Maria e do Estado do Rio Grande do Sul o fizeram contar com uma série de sujeitos homossexuais, transexuais, lésbicas e bissexuais que explicitam, como práticas de reconhecimento social, suas condições vida contrastantes da ordem heterossexual compulsória vigente e que apresentam sempre participativos nas atividades acadêmicas do grupo. Por outro lado, o grupo, no seu corpo de investigadores de iniciação científica, de mestrado e de doutorado, apresentou-se como um espaço de atração a sujeitos acadêmicos que se interessam pelas temáticas de gênero e sexualidade por se construírem como mulheres e homens lutadores à superação da ordem machista e heterossexual compulsória, seja por assumirem orientações sexuais dissidentes, sejam por viverem situações de hierarquização diferencial das expressões de gênero, sexualidade, etnia e classe social. Dessa forma, o laboratório se identifica por uma possibilidade de resgate de um rico conjunto de narrativas sobre os processos reais de hierarquização e marginalização das expressões de gênero e sexualidade e as rupturas desta ordem a partir das memórias coletivas sobre situações práticas de vida. 
Nossas estratégias, então, foram: apresentar as situações reais de vida dos sujeitos pesquisadores e suas relações de intimidade com a temática de pesquisa; a contribuição de sujeitos LGBT's conhecidos na cidade de Santa Maria, pelo envolvimento do grupo em atividades de extensão; resgatar o conjunto de discursos de narrativas trazidas de outros contextos pelas atividades diversas de pesquisa. Além disto, os processos de ruptura estabelecidos pelas sexualidades dissidentes podem também ser visualizados por um rico material imagético, publicitário, cinematográfico e midiático encontrado na internet: pequenos documentários que trazem sujeitos reais e suas experiências de vida; obras cinematográficas de ficção que abordam realidades genéricas vividas sobre tais situações de ruptura; propagandas e materiais publicitários produzidos por entidades feministas e do movimento LGBT, que abordam situações de preconceito e discriminação, assim como de empoderamento das mulheres e das diferentes sexualidades. Além disto, a literatura científica na área da psicologia, psicologia social, antropologia, sociologia e ciências humanas nos permitem acessar trabalhos que evidenciam, de forma ética, narrativas estruturadas em formas de discussão dos processos de identificação dissidentes (hierarquização, marginalização, empoderamento e estabelecimento de novas centralidades) de sujeitos marginais ao machismo e a heterossexualidade compulsória. É, assim, que o material de ação se constituiu pela produção e emergência de novos discursos que romperiam com a ordem simbólica hegemônica sobre as expressões de gênero e sexualidade, explorando um pouco do drama de se viver situações marginais, mas aprofundando-se nas situações de ruptura destas condições, criando novas ordens dissidentes dos discursos primeiros.

O material de um conjunto de narrativas poderia então ser resgatado pelo grupo: as experiências reais de seus sujeitos, as narrativas registradas de pesquisas anteriores, a contribuição de sujeitos LGBT's de Santa Maria, que se envolvem nas atividades do grupo, e em materiais publicitários e cinematográficos selecionados. No entanto, teríamos que organizar um sentido da disposição destas narrativas que possibilitassem explicitar os dois grandes eixos das ações de ensino na escola: os processos simbólicos contidos nas relações sociais que marginalizam e hierarquizam certas expressões de gênero e sexualidade e as rupturas simbólicas contidas nas experiências práticas de emergência de outras sexualidades de sujeitos dissidentes. Nossos dois eixos teóricos que articularam e deram sentidos as estratégias de ensino foram a teoria do reconhecimento social (HONNETH, 2003) e os processos de construção da identidade homossexual (WEEKS, 1999; COSTA, 1992; PEREIRA, AYROSA, OJIMA 2006).

A esfera do reconhecimento individual e da construção da identidade se destaca por uma discussão a respeito da ampliação das possibilidades de reconhecimento daquilo que 
se constrói como diferenças - ambas balizadas nas esferas normativas de suas construções -, mas também a ampliação dos próprios sentidos destas diferenças, o que almeja possibilidades de critica sobre o reforço das polarizações construídas pelos próprios processos normativos. A teoria crítica do reconhecimento social de Honneth (2003), muito baseadas na leitura de Hegel e Mead, destaca processos de ampliação social do reconhecimento no estabelecimento de esferas de individuação: a esfera amorosa, a esfera jurídica e a impregnação dos sentidos dos direitos de reconhecimento aos outros todos sociais. Estas esferas, além de serem construções teóricas que implicam uma explicação sobre os processos de individuação das diferenças subordinadas socialmente, nos fornecem "pistas" metodológicas que organizaram nossas formas de entender o processo de ensino que remeteu, no caso do projeto de ensino e extensão, a construção discursiva "contra-hegemônica" dos discursos de padronização e normalização das sexualidades dentro da escola.

A primeira esfera se refere ao reconhecimento amoroso que remete "as ligações emotivas fortes entre poucas pessoas, segundo o padrão de relações eróticas entre dois parceiros, de amizade e de relações pais e filhos" (HONNETH, 2003, p. 159). Esta representa a primeira etapa do reconhecimento recíproco nos quais as carências mútuas são percebidas e possíveis de serem confirmadas, satisfeitas e correspondidas. Seriam, então, as possibilidades de ter e ser objeto de estima em meio a um conjunto de receios e impedimentos de expressão e visibilidade da subjetividade, principalmente as dissidentes dos discursos nomalizadores e compulsórios. O reconhecimento amoroso, segundo Hegel (apud HONNETH, 2003, p. 160), é concebido como um "ser-si-mesmo em um outro", o que define uma ruptura entre o autoabandono produzido pelas normas sociais e os processos de autoafirmação. Esta ruptura organiza conjuntos efêmeros espaço e temporalmente produzidos de reconhecimento recíproco e de fortalecimento mútuo de afirmação e empoderamento para constituir individualidades sadias perante as intempéries do social. $\mathrm{O}$ amor romântico e as relações de amizade fortalecem a autoafirmação e reconhecimento da diferença marginal e instauram, na subjetividade dos sujeitos desejantes em construção, um “ 'poder-estar-só' comunicativamente protegido" (WINNICOTT apud HONNETH, 2003, p. 174). Isto acarreta uma fonte de libertação e de possibilidades de relacionar-se de forma mais tranquila consigo mesmo. A proteção "primária” das relações eróticas, das amizades e da família possibilita um ato de "deslimitação reciproca" que reforça o engajamento na tensão comunicativa do tecido social e na construção da individualidade.

Esta esfera primária é importante balizadora na construção de processos de ensino para a diversidade e desconstrução do preconceito e discriminação, porque muitas são as experiências perturbadoras que acompanham esta fase importante do reconhecimen- 
to individual, como, por exemplo, a não-aceitação da família, mas o encontro do refúgio das amizades e da construção de relacionamentos eróticos, ou vice-versa. Esta esfera representa as modulações espaço-temporais dos conflitos, rupturas, desesperos e também possibilidades importantes de libertação dos sujeitos em processo de individuação. A visibilidade sobre estes conflitos, no caso da construção da vida homossexual, irá permitir processos de aprendizagem pela sensibilização e comoção sobre os problemas dos outros que, como um reflexo de múltiplos espelhos (múltiplas outras formas de discriminação), tornam emergentes os sofrimentos e recalques daqueles que estão assistindo. A prática de tornar visível os casos de reconhecimento e não-reconhecimento recíproco de histórias de vida de sujeitos orientados sexualmente para o mesmo sexo pode instaurar, em ambiente escolar, comoções e possibilidades "de se colocar no lugar do outro" e, assim, disseminar processos de reconhecimento sobre as limitações próprias como do outro discriminado.

A esfera jurídica representa a constituição de um campo de obrigações quanto ao respectivo "outro" (a alteridade e as obrigações e limites quanto a esta) que inversamente nos permite avaliar as concepções e "verdades" construídas em nós mesmos (HON$\mathrm{NETH}, 2003$, p. 179). A esfera legal do reconhecimento social enseja que ocorra um reconhecimento mútuo das individualidades sem permear as necessariamente a estima, que é produto da primeira esfera, mas nos leva a um conjunto de limites quantos aos processos de negação e intolerância que, neste viés, culminaria no reconhecimento das nossas próprias limitações quanto aos aspectos da diversidade. De certa forma, as organizações jurídicas quanto ao reconhecimento possibilitam um retorno de pensamento quanto às causas de nossas intolerâncias e negações e refletem a organização de processos de empatia e critica das nossas limitações como seres de relações sociais. O processo pode permitir remodelação de nossas formas de agir quando as expressões que pretensamente nos ferem, levando-nos ao questionamento das origens destas feridas.

É claro que este desenvolvimento jurídico é ainda uma realidade brasileira frágil, porque necessita a discussão e aplicação em uma série diversa de situações de não-reconhecimento em que os estudos interculturais e pós-estruturalistas estão ainda se debatendo: as faces dos "não-reconhecimentos" dependem de uma série de sobreposições quando às situações de preconceito de discriminação que ligam diferentes elementos dos processos identitários, como as relações entre gênero, orientação sexual, racialidade e classe social (CHENSHAW, 2010). As esferas jurídicas existentes na sociedade brasileira, que ainda são muito incompletas, mas já definem jurisdições sobre casos de racismo e homofobia (embora ainda não criminalizada evidentemente), permite traçar parâmetros legais aos casos de discriminação dentro da escola. Inclusive as insuficiências legais nos permitem de- 
bater as condições diversas de formulação e relações morais das incompatibilidades e incompletudes das leis, isto porque documentos oficiais de organizações e instituições de luta contra o machismo, a homofobia e racismo permitem ampla visualização de casos de violência contra a diversidade. Estes documentos oficiais são importantes para ampliação da discussão na escola sobre a necessidade de reformulação da lei quanto as diferentes situações sociais de preconceito e crime contra a integridade humana.

A esfera social representa, finalmente, a construção de uma estima social que permite as alteridades se construírem como indivíduos. Isto implica então a diversificação de valores socialmente construídos, sendo que, "quanto mais as concepções dos objetivos éticos se abrem a diversos valores e quanto mais a ordenação hierárquica cede a uma concorrência horizontal, tanto mais estima social assumirá um traço universalizante e criará relações simétricas" (HONNETH, 2003, p. 200). Esta discussão sobre ética, hierarquia social e construções diversas de valores dispostos de forma horizontal é um desafio na escola. Em primeiro lugar é necessário construir um conjunto de formas de entendimento sobre as belezas das diferentes expressões dos grupos sociais: como a beleza expressa nas diferentes etnicidades e racialidades, as belezas existentes nas culturas produzidas por diferentes contextos significativos quanto às diversidades de orientação sexual e expressões de gênero, as criatividades e expressões geracionais, etc. A construção destas evidências sem hieraquizá-las e sem entrar no mérito do folclore, encontrando sujeitos expressivos reais e falando de suas experiências de vida, permite almejar a construção de uma alta autoestima social quanto à diversidade. A valorização das pluralidades culturais deve ser tratada no conjunto dos sofrimentos quanto às resistências à aceitação social, mas também pela bravura de luta contra o preconceito e na realização dos casos e situações de livre expressão. Talvez a escola seja aquela instituição social que irá permitir traçar as bases desta estima social em relação à diversidade, se realmente estabelecer projetos que as tratem além das formas folclóricas através do contato real e a organização de processos de mútua admiração.

Para tentar operacionalizar estas esferas de reconhecimento como método de tratar as relações de discriminação das homossexualidades na escola, pensamos em outras esferas de maior realização quanto ao acesso as subjetividades de sujeitos homossexuais. A principal ideia emergente foi em tratar as histórias de vida, as tramas, as rupturas, os sofrimentos e os encorajamentos de sujeitos orientados sexualmente para o mesmo sexo. Para isto teríamos de organizar formas discursivas (falas, imagens, relatos de experiência, abordagens ficcionais filmográficas) em um sentido didático para representar e valorar a construção da homossexualidade (por um lado sensibilizar aos sofrimentos relativos ao 
preconceito e discriminação social em diferentes situações sociais, por outro lado mostrar a beleza da individuação e da possibilidade de expressão de amor, desejo e formas estéticas). A organização didática dos discursos e narrativas dos sujeitos sociais e suas representações, no sentido de ampliar processos escolares de valoração da diversidade de orientações sexuais, vieram com a temática da construção da identidade homossexual. Foi assim que nos centramos em três textos sobre tal construção e suas problemáticas: Weeks (1999); Pereira, Ayrosa e Ojima (2006) e Nunan (2003).

Plummer (apud WEEKS, 1999), tratam da construção da identidade homossexual pelo viés da estigmatização. A respeito da identidade estigmatizada são verificados basicamente quatro estágios: o de sensibilização (o indivíduo torna-se consciente da sua diferenciação ao ser rotulado diretamente perante as relações sociais face a face), o de significação (atribui sentido a essa diferença, torna-se consciente das possibilidades do mundo social), de subculturização (reconhecimento de si mesmo a partir do envolvimento com os outros) e de estabilização (estágio de plena aceitação). Podemos dizer que os dois primeiros estágios remetem a processos subjetivos de introspecção de aspectos de uma identidade estigmatizada por rotulações sociais. Os outros dois estágios remetem à identificação com outras pessoas, que passaram por processos parecidos de sensibilização e significação da diferença, e ao encontro e a existência de lugares que possam promover à imersão em práticas culturais que dão força às significações. O espaço, neste processo, torna-se elemento crucial da existência da alteridade cultural, assim como de sua continuidade e expansão. Britzmann (1999, p. 80) argumenta que "a identidade sexual é social e depende de comunidades e locais onde haja práticas, representações e discursos comuns” (grifo meu).

A construção da identidade homossexual, segundo Pereira, Ayrosa e Ojima (2006), citando Numan (2003), implica um desenvolvimento em quatro estágios: a sensibilização, quando acontece o processo de marginalização em relação a expressão de alguns elementos diferenciados do sujeito, principalmente alguma dissidência das conformidades dadas aos gêneros; a confusão, quando o sujeito subjetivamente encontra-se confuso quanto as revelações dos seus desejos e os processos de imposição social sobre a normalidade heterossexual e o desvio homossexual, gerando experiências sexuais-afetivas difusas e processos de encobrimento e aceitação difícil da sexualidade; identidade, quando o sujeito aceita-se finalmente e se identifica a outros como homossexual, sendo reforçado pelos processos de socialização com outros sujeitos homossexuais, nos quais grupos, namorados e lugares de sociabilidade tornam-se importantes a este processo; compromisso, que implica uma defesa de si e de outros sobre o reconhecimento das homossexualidades, denotando o repúdio de investimentos ofensivos contra a liberdade de sua expressão e a assunção de uma defesa de sua integridade identitária. 
Estes "estágios" de desenvolvimento da identidade homossexual representam a especificidade de serem construídos por uma base marginalizada pelos discursos normalizadores que constroem os próprios atos, processos e estéticas de transgressão à regra. $\mathrm{O}$ sentido destas construções, como vimos, remete o reforço dos modelos de heterossexualidade compulsória, tornando norma estes modelos perante as relações sociais comuns em diferentes ambientes sociais. Por outro lado, uma ruptura ao modelo primeiro (que por outro lado reforça as polarizações entre realidades normalidades e realidades desviantes, que representam repetições de conjuntos simbólicos compulsórios) é seguida pela realização da assunção do modelo transgressivo criado, que gera o corpo e gera os atos dos sujeitos. Porém, os sujeitos, em processo de sofrimento devido a discriminação e pressão sofrida, readéquam estes atributos e preceitos para se reconstruírem mediante uma autoafirmação: seguem os modelos criados pela ordem heterossexista, mas reativam sintomas de ruptura pelos processos estabelecidos por esta própria ordem. Estas “realizações” simbólicas dialéticas são evidencias experienciais diretamente guardadas nas memórias dos sujeitos orientados para o mesmo sexo e permeiam seus diferentes atos de vida que se distribuem de forma acumulada em processos de reconhecimento que marcam a literatura, processos científicos dissidentes, arte e produção midiática.

É possível organizar, como evidencias didáticas deste processo, um conjunto de materiais, de imagens, de documentários, de obras cinematográficas, de textos, de frações de narrativas, etc, contidas em diferentes meio de divulgação (artigos acadêmicos, livros, curtas metragens de cinema, arte cênicas e visuais, etc). Além disso, estas realizações são realidades de memória de fácil emergência de sujeitos reais, pois representam fases e experiências cruciais de construção de vida. Atividades de pesquisa e coletas de narrativas podem ser organizadas mediante estabelecimento de indicadores acordados mediante as fases de desenvolvimento da identidade homossexual, assim como os discursos de sujeitos colaboradores que lutam pelo reconhecimento das homossexualidades tem o maior prazer e disponibilidade em contribuir com suas estórias de vida a processos de ensino e aprendizagem. Foi assim que desenvolvemos os processos de ensino, tomando como base a teoria sobre as esferas de reconhecimento social e os "estágios" de construção da identidade homossexual, organizando diferentes intervenções com alunos e professores que remetiam a atenção a um processo e outro. Lembramos que as estratégias foram sempre de sensibilização sobre as dificuldades e sofrimentos destes sujeitos, para tornar visível e relacional outras formas de sofrimentos de sujeitos não homossexuais, mas a beleza dos atos de empoderamento, a criação de imaginações, a produção de novas formas estéticas e as criações de embelezamento autênticos da vida cotidiana (a diversidades expressivas das formas de expressão da cultura LGBT) também 
devem e foram valorizadas para a criação de uma alta autoestima social quanto as diversidades de sujeitos e suas orientações sexuais.

É claro que irão existir rupturas e insuficiências no processo. A primeira insuficiência é tratar a construção das fases de reconhecimento e dos estágios de construção da identidade homossexual como teorias universais que podem polarizar ainda mais as sexualidades. Isto ficou evidente no processo de ensino na Escola de Santa Maria, pois, como defende Bulter (2010), a construção das sexualidades remete a um universo plural que distingue os sujeitos e os espaços de vivência. A autora aproxima seu discurso da ordem fenomênica. As sexualidades são atravessadas por outros elementos de identidade, como gênero, raça, etnia, classe, crenças, culturas locais e geracionais. A grande diferença sobre o tratamento da sexualidade na escola veio com processos diferenciados de entendimento entre professores e alunos, denotando uma diferença quanto à ordem geracional dos sujeitos envolvidos (mais rigidamente demarcada entre professores, até por suas necessidades de gerenciar de forma mais eficaz a ordem escolar). As outras diferenças foram as expressões de homossexualidades e envolvimentos distintos entre homens adolescentes gays, meninos em processo de transexualização e lésbicas, que constroem grupos distintos de reconhecimento amigável para se proteger da ordem hegemônica e cujos diálogos entre as homossexualidades torna-se difícil.

O maior desafio encontrado neste processo de ensino foi a relação estreita com a religiosidade desta população de periferia, que torna excessivamente marcada nos discursos e expressões de adolescentes na sala de aula. Muitas vezes as aulas sobre gênero e sexualidade se desviaram para as discussões de disputas entre diferentes esferas simbólicas das diferentes crenças religiosas expressas ali, principalmente no contraste entre sujeitos que mantinham proximidade com as religiosidades afro-brasileiras e outros sujeitos que se identificavam como evangélicos e neopentecostais. Os conflitos de ordem das crenças religiosas permeavam constantemente as discussões sobre as expressões de gênero e sexualidade, porque elas envolvem significações distintas sobre o assunto. Este ponto até criou certas indisposições do projeto quanto às posições de ordem na escola, sendo, muitas vezes sugerido, não tratar a fundo as questões religiosas, que percebemos ser mais problemática efetivamente do que tratar sobre homossexualidade. No entanto, separar o contexto religioso das discussões referentes às hierarquias sexuais se tornou impossível nesta realidade, o que nos fez diversas vezes deixar o debate entre disposições religiosas sobre as sexualidades e as normas de gênero se desenvolverem fluidamente, até como forma de aprendizado dos sujeitos pesquisadores envolvidos. O fato é que o modelo teórico e didático adotado foi pertinente para fazer emergir tais diversidades e poder construir um conhecimento mais ampliado sobre 
a realidade de construção de sexualidade dos diferentes sujeitos envolvidos na comunidade escolar. A universalidade da teoria e do método proposto pelas discussões de reconhecimento social e de construção de identidade homossexual foram, então, tidas como modelos iniciais para conseguir se chegar as especificidades da comunidade escolar em questão, fazendo emergir diferentes questões por estarem conectadas a construção das homossexualidades.

\section{CONSIDERAÇÕES FINAIS}

O texto discutiu primeiramente as concepções sobre gênero e sexualidade pautando as construções simbólicas que elas evidenciam. Ao tratar gênero e sexualidade em relação à ordem simbólica, pensamos as disparidades e rupturas teóricas na construção de diversidades de expressão de sexualidade e formas diferentes de realização da ordem simbólica, em contraste da persistência da ação de organização discursiva em situações reais da heterossexualidade e do machismo compulsórios. Observamos que estes processos em contradição remetem a processos de ordem territoriais em grande escala, sendo que os contextos de linguagem e de interações sociais diretas entre diferentes sujeitos sociais mobilizam formas de integração a normativas sexuais e formas de ruptura e dissidência destas normalizações. Se existem territórios simbólicos em conflitos que estão neste sintoma pela realização simbólica dos agentes sociais em interação, a escola poderá ser visto como um território relacional de objetivação de conflitos simbólicos dissidentes expressões pelas ações dos sujeitos sociais.

Definindo esta relação entre geografia e estudos de gênero e sexualidade, pautamos os desafios do projeto Prolicen que procurou pelo viés geográfico tratar gênero e sexualidade na escola do bairro Santa Marta, em Santa Maria-RS, no ano de 2015. Discutimos as estratégias de ação que envolveu as construções de narrativas de sujeitos homossexuais reais (estudantes e professores, membros de coletivos e organizações sociais políticas LGB$\mathrm{T}$ 's) e de outras formas narrativas trazidas da literatura científica, das artes, do cinema e da mídia. O desafio de organizar o processo de ensino pautado em narrativas estabeleceu-se pelos vieses das teorias e pistas metodológicas contidas nos trabalhos sobre políticas do reconhecimento social e políticas de construção da identidade homossexual. A partir destas construções, argumentamos os processos de envolvimento e organização dos processos de ensino e evidenciamos limites desta estratégia, principalmente os contrastes e a evidencia que os processos de construção das homossexualidades são contextuais e relatados de formas plurais pelos sujeitos escolares envolvidos. É finalizando este ensaio que desejamos que o mesmo venha a contribuir com as estratégias de tratar junto a outros espaço e tempos escolares as questões de reconhecimento social das homossexualidades. 


\section{REFERÊNCIAS}

1. BEAUVOIR, Simone. O segundo sexo. Rio de Janeiro: Nova Fronteira, 1980.

2. BRITZMAN, D. P. O que é esta coisa chamada amor: identidade homossexual, educação e currículo. Revista Educação e Realidade 21(1), 71-95, jan-jun, 1999, Porto Alegre.

3. BUTLER, Judith. Problemas de gênero: feminismo e subversão da identidade. Rio de Janeiro: Civilização Brasileira, 2010.

4. CRENSHAW, Kimnerl. Documento para o encontro de especialistas em aspectos da discriminação racial relativos ao gênero. Revista Estudos Feministas. Ano 10. Florianópolis: primeiro semestre, 2002.

5. ENGELS, F. A origem da família, da propriedade privada e do estado. Rio de Janeiro: Civilização Brasileira, 1982.

6. FOUCAULT, M. História da sexualidade: a vontade de saber. Rio de Janeiro: Graal, 1988. V. 1.

7. GARFINKEL, H. Estudios en etnometodología. México/Bogotá: Anthropos Editorial, 2006.

8. GIDDENS, Anthony. A Transformação da Intimidade: Sexualidade, Amor e Erotismo nas Sociedades Modernas. São Paulo: Ed. Unesp, 1993.

9. HELLER, A. Sociologia de la vida cotidiana. Barcelona: Península, 1991.

10. HONNETH, A. Luta pelo reconhecimento: a gramática moral dos conflitos sociais. São Paulo: Editora 34, 2003.

11. LOURO, G. L. Gênero, sexualidade e educação: uma perspectiva pós-estruturalista. Petrópolis: Vozes, 1997.

12. MASSEY, D. Pelo espaço: uma nova política da espacialidade. Rio de Janeiro: Bertrand Brasil, 2009.

13. NUNAN, A. Homossexualidade: do preconceito aos padrões de consumo. Rio de Janeiro: Caravansarai, 2003.

14. PEREIRA, Bill; AYROSA, Eduardo André Teixeira; OJIMA, Sayuri. Consumo entre gays: compreendendo a construção da identidade homossexual através do consumo. Cadernos EBAPE.BR. Volume 4. Número 2. Rio de Janeiro: FGV, junho de 2006.

15. RAFFESTIN, C. Por uma geografia do poder. São Paulo: Ática, 1993.

16. SILVA, Tomaz Tadeu da. A produção social da identidade e da diferença. In: SILVA, T.T. (Org.). Identidade e diferença. Petrópolis: Vozes, 2000, p. 73-102.

17. TEDESCO, João Carlos. Paradigmas do cotidiano: introdução à constituição de um campo de análise social. Passo Fundo: Edunisc, UPF, 2003.

18. WEEKS, J. O corpo e a sexualidade. In LOURO, G. L. (org.). O corpo educado. Belo Horizonte: Ed. Autêntica, 1999.

Artigo recebido em 25 de agosto de 2016.

Artigo aceito em 07 de setembro de 2016. 